\title{
Apparent Diffusion Coefficient of Sodum Chloride in Cubical Agar Gel
}

\author{
Sachiko Odake, Keiko Hatae, Atsuko Shimada \\ and Sadaaki IrBUCHI* \\ Department of Food \& Nutrition, Faculty of Home Economics, Ochanomizu University, \\ Bunkyo-ku, Tokyo 112, Japan \\ * Department of Domestic Economy, School of Literature \& Domestic Economy, \\ Wayo Women's University, Ichikawa-shi, Chiba 272, Japan
}

Received April 16, 1990

\begin{abstract}
Cubes of $2 \%$ agar gel, with side lengths $(2 L)$ of $1,2,3,5,7$ and $10 \mathrm{~cm}$, were soaked in a $0.1 \mathrm{M}$ sodium chloride solution at $25^{\circ} \mathrm{C}$. After soaking for $0-75 \mathrm{hr}(t)$, the amounts of sodium chloride and water in the gel were measured, and the mean concentration of the sodium chloride in the gel cube was calculated. The ratio of the mean concentration to the boundary concentration $\left(C_{\mathrm{r}}\right)$ depended on the value of $t / L^{2}$. The value for the apparent diffusion coefficient $\left(D_{\text {app }}\right)$, which was yielded by substituting the values of $t / L^{2}$ and $C_{\mathrm{r}}$ into the solution of the diffusion equation, depended on $t / L^{2}$ and $C_{\mathrm{r}}$, and reached the maximum value $\left(1.03 \times 10^{-5} \mathrm{~cm}^{2} / \mathrm{sec}\right)$ at about $C_{\mathrm{r}}=0.6$. The relationship between $C_{\mathrm{r}}$ and $D_{\mathrm{app}} t / L^{2}$, which is shown in this paper, can be applied to the diffusion of any substance in various food materials other than agar gels or sodium chloride.
\end{abstract}

The transport of mixing additives, seasonings, water or vapor in foodstuffs plays an important part in cooking and food processing. In order to describe the transport of the latter quantitatively, it is necessary to know the apparent diffusion coefficient $\left(D_{\mathrm{app}}\right)$ of the diffusing substances. The transport and $D_{\text {app }}$ value of cyclohexanol in potatoes ${ }^{1)}$ or the $D_{\mathrm{app}}$ of sodium chloride in cheese during salting ${ }^{2)}$ have been reported. The reduced water activity in meat during soaking in a sodium chloride-glycerol solution has been studied, the $D_{\text {app }}$ of the solute being measured by using a beef plane sheet. ${ }^{3)}$ Besides real foods, various gels have also been used to study diffusion phenomena because of their isotropy. The $D_{\text {app }}$ of sodium ion in 1-4\% agar gels has been reported, ${ }^{4-6)}$ and $G$. Djelveh et al. ${ }^{7)}$ improved the rapid determination of $D_{\text {app }}$ in gels and recently reported the $D_{\mathrm{app}}$ of sodium chloride in a $3 \%$ agar gel. The diffusion of various different homologous series ( $n$-alcohols, polyhydric alcohols, oligosaccharides and alkali metal chlorides) in cellulose gels has been reported ${ }^{87}$ and the $D_{\text {app }}$ of glucose in carrageenan gels was obtained. ${ }^{9)}$ In all these reports, the diffusion flow was designed to occur in one direction, and it was assumed that the $D_{\text {app }}$ value was constant during the experiments. Therefore, the $D_{\text {app }}$ obtained by such methods indicates the degree of interference from the matrix of foods or gels. On the other hand, in most cooking or food-processing operations, the diffusing substances penetrate the materials in all directions from the surface to the center. Therefore, each diffusion flow affects the other flows. Consequently, the $D_{\text {app }}$ in three-dimensional diffusion must be different from that obtained in an one-dimensional diffusion system. Furthermore, since each diffusion flow changes with the time elapsed because of the mutual distrurbance, $D_{\text {app }}$ is also thought to depend on time.

For three-dimensional diffusion, the $D_{\text {app }}$ of various salts in tuna flesh has been measured. ${ }^{10,11)}$ In these studies, $D_{\text {app }}$ was calculated by assuming it to be constant during the diffusion process. When studying the threedimensional diffusion flow in a medium, the steric concentration profile therein is necessary 
for an approximate solution. Since it is difficult to obtain this, the mean concentration in the medium is often used.

This investigation was undertaken to reveal the properties of $D_{\text {app }}$ when three-dimensional diffusion occurs in media. For this purpose, the $D_{\text {app }}$ value for sodium chloride when it diffuses into $2 \%$ agar gel cubes, from the surface to the center, was studied, using the diffusion equation for the mean concentration of sodium chloride in cubes. The relationship between the size of the cube, immersion time, the mean concentration of sodium chloride in the cube and $D_{\text {app }}$ will be shown. These results can be applied to any other homogeneous cube and any other diffusion substance.

\section{Materials and Methods}

Materials. The agar was purchased from Kanto Chemical Co., Inc. The mercury(II) thiocyanate solution was prepared from $5 \mathrm{~g}$ of mercury(II) nitrate dissolved in $200 \mathrm{ml}$ of $0.5 \mathrm{M}$-nitric acid. ${ }^{12)}$ To the solution, $3 \mathrm{ml}$ of saturated ammonium iron(III) sulfate, 12-water dissolved in $1 \mathrm{M}$ nitric acid was added and the result mixed. An aqueous potassium thiocyanate solution. $(4 \% \mathrm{w} / \mathrm{v})$ was added dropwise to the mixture until the supernatant turned slightly red. The obtained precipitate was then filtered through a glass filter (G3), washed with deionized water, and dried in vacuo. A solution consisting of $0.3 \mathrm{~g}$ of the resulting powder dissolved in $95 \%$ ethanol is referred to as the mercury(II) thiocyanate solution. The ammonium iron(III) sulfate solution was prepared by dissolving $12 \mathrm{~g}$ of ammonium iron(III) sulfate, 12-water in $200 \mathrm{ml}$ of $6 \mathrm{M}$ nitrate acid. Deionized water was used throughout this study.

Preparation of the agar gel cubes. Agar powder was soaked in deionized water for one hour, dissolved at $70^{\circ} \mathrm{C}$ for $30 \mathrm{~min}$, then dissolved completely at $90^{\circ} \mathrm{C}$ for $30 \mathrm{~min}$ by using a reflux condenser, degassed under reduced pressure, and finally solidified in a stainless steel vat at $25^{\circ} \mathrm{C}$ for $12 \mathrm{hr}$. The solid content of the gel was $2 \%$ (wt/wt). Just before soaking the gel in a sodium chloride solution, the gel was cut into cubes with a knife, the side lengths of which were $1,2,3,5,7$ and $10 \mathrm{~cm}$, respectively. The surface of each cube was made as smooth as possible.

Preparation of agar gel as an infinite slab. Agar gel was similarly dissolves and solidified in a cylindrical stainless steel container, the diameter of which was $10 \mathrm{~cm}$ and height $10 \mathrm{~cm}$. An additional $3 \mathrm{~cm}$ of height was created with aluminum foil wound around the top of it. After leaving the gel at $25^{\circ} \mathrm{C}$ for $12 \mathrm{hr}$ and then cutting off the top $3 \mathrm{~cm}$, the gel was used in a diffusion experiment.

Measurement of the mean concentration in gel cubes. The agar gel cubes were soaked in a $0.1 \mathrm{M}$ sodium chloride solution at $25^{\circ} \mathrm{C}\left( \pm 0.5^{\circ} \mathrm{C}\right)$ under the conditions shown in Table I. The cubes were stood in the solutions on a network of suspended stainless steel or plastic so that sodium chloride could penetrate the cubes from every face. The solution was stirred with a magnetic stirrer.

After soaking for a prescribed period, the gel cubes were taken out of the sodium chloride solution, and weighed after the solution on the surfaces had been quickly removed with filter paper. The water content was measured by using half the number of gel cubes and drying at $70^{\circ} \mathrm{C}$ in vacuo. With the other half, the total amount of sodium chloride which had penetrated the gel cubes was next measured. Each gel cube was homogenized at $18,000 \mathrm{rpm}$ for $2 \mathrm{~min}$ with a DX-8 homogenizer (Nihonseiki Kaisha Ltd.), that was filled up to an appropriate volume with deionized water, and the homogenate was centrifuged at $5,000 \times g$ for $10 \mathrm{~min}$. To the supernatant $(2.5 \mathrm{ml})$ the following reagents were successively added: mercury(II) thiocyanate ( $1 \mathrm{ml})$, iron(III) ammonium sulfate $(2 \mathrm{ml})$, and deionized water $(7 \mathrm{ml})$. After leaving the mixed solution for $10 \mathrm{~min}$, its absorbance was determined at $460 \mathrm{~nm}$. By this measurement, the concentration of $\mathrm{Cl}^{-}$could be determined $^{12)}$ from the standard curve. Using the concentration of $\mathrm{Cl}^{-}$, the total amount of $\mathrm{Cl}^{-}$which had penetrated the cube was calculated, and the total amount of sodium chloride was then obtained from the ratio of $\mathrm{NaCl} / \mathrm{Cl}=58.44 / 35.45$. The mean concentration of sodium chloride in the cube was then calculated from the following

Table I. Conditions for Soaking the Cubes in a 0.1 m Sodium Chloride Solution

\begin{tabular}{ccccc}
\hline Example & $\begin{array}{c}\text { Size of cube } \\
(\mathrm{cm})\end{array}$ & $\begin{array}{c}\text { Number of } \\
\text { cubes }\end{array}$ & $\begin{array}{c}\text { Solution volume } \\
\text { (liter) }\end{array}$ & \multicolumn{2}{c}{$\begin{array}{c}\text { Soaking time } \\
(\text { hr })\end{array}$} \\
\hline 1 & 1 & 10 & 4 & $0-6$ \\
2 & 2 & 10 & 4 & $0-6$ \\
3 & 3 & 6 & 4 & $0-24$ \\
4 & 5 & 6 & 40 & $0-24$ \\
5 & 7 & 2 & 40 & $0-48$ \\
6 & 10 & 2 & 80 & $0-75$ \\
\hline
\end{tabular}


equation:

$$
\bar{C}(t)=M(t) /\{W \times(P / 100) / d\}
$$

$\bar{C}(t)(\mathrm{mol} / \mathrm{ml})$ is the mean concentration of sodium chloride in the cube at time $t, M(t)(\mathrm{mol})$ is the total amount of sodium chloride which had penetrated the cube at time $t$, $W(\mathrm{~g})$ is the weight of the cube, $P(\%)$ is the percentage of water content in the cube, and $d(\mathrm{~g} / \mathrm{ml})$ is the density of water. The soaking experiment was triplicated.

Fujii and Thomas ${ }^{4)}$ have mentioned that agar gel was a cation exchanger. According to our preliminary investigation, however, there was only a negligible difference between the concentration of $\mathrm{Na}^{+}$measured by atomic absorbance flame photometry (Shimadzu AA-660) and $\mathrm{Cl}^{-}$measured as already described after soaking the agar gel in the sodium chloride solution.

Measurement of the concentration gradient in a semiinfinite gel slab. The agar gel slab in the stainless steel container was soaked horizontally in 51 of $0.1 \mathrm{M}$ sodium chloride solution at $25^{\circ} \mathrm{C}$ for $1,3,6,9$ or $12 \mathrm{hr}$, the solution being stirred with a mangnetic stirrer. After soaking, the gel was removed from the stainless steel container, and a small cylindrical section of $2.83 \mathrm{~cm}$ diameter was cut out from the center of the gel (Fig. 1a). This part had not been influenced by diffusion flow from the side of the gel, which could be caused by the capillary phenomenon occurring in the slight peripheral gap between the gel and the container. The cut-out cylindrical gel sample was sliced into 6 disks of $0.5 \mathrm{~cm}$ thickness, in the direction away from the surface in contact with the sodium chloride solution (Fig. Ib). Each disk was cut in half, one half being measured for water content and the other half for the mean concentration of sodium chloride in the same manner as that used for the cubes

Solution of the diffusion equation for cubical media. A solution of the diffusion equation concerning the mean concentration in a rectangular parallelepiped has been expressed as the product of three one-variable problems

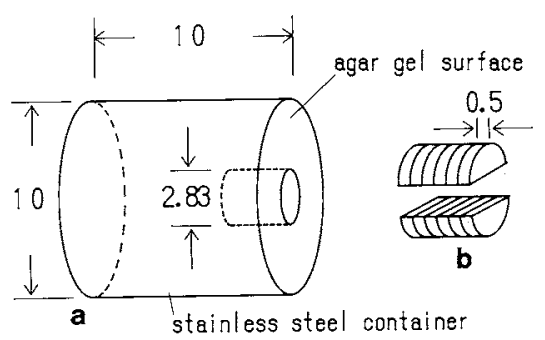

Fig. 1. Schematic Diagram for the Measurement of Concentration Gradient in a Semi-infinite Gel Slab.

The unit in the figure is $\mathrm{cm}$ : a, stainless steel container in which the agar gel slab was contained; $b$, cut-out cylindrical sample which was used for measuring the concentration gradient of sodium chloride. by R.B. Bird, W. E. Stewart and E. N. Lightfoot ${ }^{13)}$ as follows:

$$
\begin{aligned}
& \text { boundary conditions: } C(x, y, z, t)=C_{1}, \\
& \quad x= \pm a, y= \pm b, z= \pm c, t>0 \\
& \text { initial conditions: } C(x, y, z, t)=C_{0}, \\
& \quad-a<x<a,-b<y<b,-c<z<c, \quad t=0 \\
& \frac{C_{1}-\bar{C}(t)}{C_{1}-C_{0}}=8 \sum_{m=0}^{\infty} \sum_{n=0}^{\infty} \sum_{p=0}^{\infty} \frac{1}{(m+1 / 2)^{2}(n+1 / 2)^{2}(p+1 / 2)^{2} \pi^{6}} \\
& \times \exp \left\{-\left(\frac{(m+1 / 2)^{2}}{a^{2}}+\frac{(n+1 / 2)^{2}}{b^{2}}+\frac{(p+1 / 2)^{2}}{c^{2}}\right) \pi^{2} D t\right\}
\end{aligned}
$$

where $\bar{C}(t)$ is the mean concentration in a rectangular parallelepiped at time $t$. Symbols $a, b$ and $c$ are half of the side length of the rectangular parallelepiped, $D$ is the diffusion coefficient, and $C_{1}$ and $C_{0}$ are the boundary and initial concentrations, respectively. Substituting the half side length of the cube $(L)$ for the rectangular parallelepiped ( $a, b$ and $c$ ) in Eq. (4), the following equation was obtained:

$$
\begin{aligned}
& \frac{C_{1}-\bar{C}(t)}{C_{1}-C_{0}}=8 \sum_{m=0}^{\infty} \sum_{n=0}^{\infty} \sum_{p=0}^{\infty} \frac{1}{(m+1 / 2)^{2}(n+1 / 2)^{2}(p+1 / 2)^{2} \pi^{6}} \\
& \times \exp \left[-\left\{(m+1 / 2)^{2}+(n+1 / 2)^{2}+(p+1 / 2)^{2}\right\} \pi^{2} D t / L^{2}\right]
\end{aligned}
$$

The approximate solution obtained in this study was from Eq. (5), in which $\bar{C}(t)$ is the mean concentration in the cube at time $t$ described in Eq. (1), and $L$ is the half side length of the cubes $(0.5-5 \mathrm{~cm})$ employed in the experiment. The initial condition $C_{0}$ was zero and the boundary condition $C_{1}$ was $1 \times 10^{-4} \mathrm{~mol} / \mathrm{ml}$ in this study.

Solution of the diffusion equation for a semi-infinite slab. The solution of the diffusion equation for a semi-infinite slab under

boundary conditions: $C=C_{1} \quad x=0, \quad t>0$

and

initial conditions: $C=C_{0} \quad x>0, \quad t=0$

was given by $\mathrm{Crank}^{14)}$ as:

$$
\left\{C_{1}-C(x, t)\right\} /\left(C_{1}-C_{0}\right)=\operatorname{erf}\{x / 2 \sqrt{D t}\}
$$

where $C(x, t)$ is the concentration of the diffusion substance at distance $x$ and time $t$.

For an approximate solution of Eq. (8), $C(x, t)$ was assumed to be the mean concentration of sodium chloride at the center of the sliced disks (Fig. 1b); i.e., 0.25, 0.75, $1.25,1.75,2.25$, and $2.75 \mathrm{~cm}$ from the surface.

\section{Results}

Change of the mean concentration in the gel cubes

The change of $C_{\mathrm{r}}$ for the various agar gel 


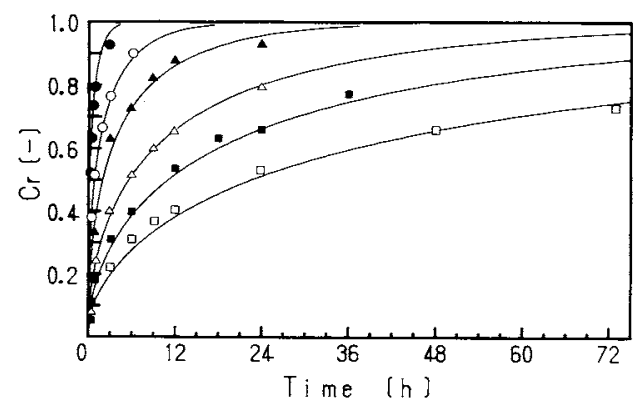

Fig. 2. Changes in the $C_{\mathrm{r}}$ of Various Agar Gel Cubes after Soaking in a $0.1 \mathrm{~m}$ Sodium Chloride Solution.

The solid curves represent the calculated value from the relationship between $C_{\mathrm{r}}$ and $D_{\text {app }}$ shown in Fig. 6. Symbols in the figure are:, $1 \mathrm{~cm} ; \bigcirc, 2 \mathrm{~cm} ; \Delta, 3 \mathrm{~cm} ; \triangle, 5 \mathrm{~cm}$; $7 \mathrm{~cm} ; \square, 10 \mathrm{~cm}$ in side length of the cubes.

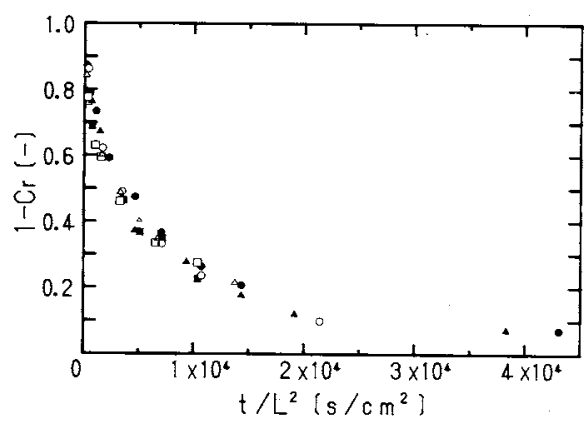

Fig. 3. Relationship between $1-C_{\mathrm{r}}$ and $t / L^{2}$.

Symbols are the same as those shown in Fig. 2. The value for $1-C_{\mathrm{r}}$ is a function of the value for $t / L^{2}$ regardless of the size of the cube.

cubes after soaking in a $0.1 \mathrm{M}$ sodium chloride solution are shown in Fig. 2. $C_{\mathrm{r}}$ represents the ratio of the mean concentration of sodium chloride in the gel cubes to its boundary concentration; i.e., $C_{\mathrm{r}}=\bar{C}(t) / C_{1}$. The smaller cube took a shorter time to attain equilibrium; i.e., $C_{\mathrm{r}}=1$.

\section{Relationship between $C_{\mathrm{r}}$ and $t / L^{2}$}

The relationship between $C_{\mathrm{r}}$ and $t / L^{2}$ is shown in Fig. 3. It can be recognized that the value of $1-C_{\mathrm{r}}$ is a function of the value of $t / L^{2}$ regardless of the the size of the cube.

\section{Calculation of $D_{\text {app }}$ from the relationship between $C_{r}$ and $t / L^{2}$}

Since, in this study, initial concentration $C_{0}$

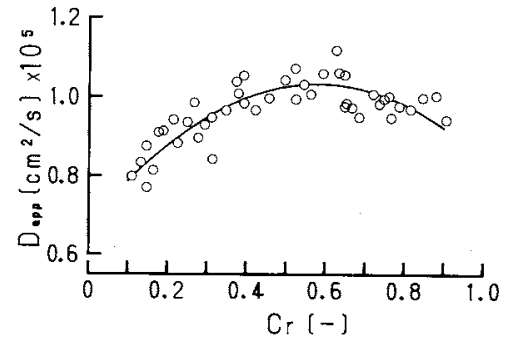

Fig. 4. Change of $D_{\text {app }}$ for Three-dimensional Diffusion. Dots are the value for $D_{\text {app }}$ obtained by substituting the values for $t / L^{2}$ and $C_{\mathrm{r}}$ in Eq. (5). The calculated value for $D_{\text {app }}$ is shown in the solid curve as a quadratic equation of $C_{\mathrm{r}}: D_{\mathrm{app}}=A \times C_{\mathrm{r}}{ }^{2}+B \times C_{\mathrm{r}}+C$, where $A=-1.064 \times$ $10^{-5}, B=1.236 \times 10^{-5}$, and $C=6.738 \times 10^{-6}$.

was zero, $1-C_{\mathrm{r}}$ expresses the non-dimensional concentration on the left-hand side of Eq. (5). Therefore, diffusion coefficient $D_{\text {app }}$ was calculated by substituting the experimental values for $C_{\mathrm{r}}$ and $t / L^{2}$ into Eq. (5). Since $D_{\mathrm{app}}$ for cubes was thought to depend on $t / L^{2}$ or $C_{\mathrm{r}}$, as mentioned before, the value for $D_{\text {app }}$ was calculated from 48 individual experimental data (represented in Fig. 3.) $D_{\text {app }}$ was calculated by taking the first 4 data from the left as one set to make Eq. (5) best fit these 4 data, then another set was formed by taking the last 3 data of the first set and adding to the next datum moving right, its $D_{\text {app }}$ being calculated in the same way, and so on. Thus, the value for $D_{\text {app }}$ corresponding to these small sets of $t / L^{2}$ or $C_{\mathrm{r}}$ could be approximated. When the number of data in a set was smaller, the value for $D_{\text {app }}$ was so widely scattered that the dependency of $D_{\text {app }}$ on $t / L^{2}$ or $C_{\mathrm{r}}$ could not be recognized. The calculated $D_{\text {app }}$ versus $C_{\mathrm{r}}$ is shown by circles in Fig. 4. The value for $C_{\mathrm{r}}$ in Fig. 4 represents the mean value of the four data in each set. The value for $D_{\mathrm{app}}$ completely converged when $m, n$ and $p$ in Eq. (5) became greater than 7 or 8 . The value for $D_{\text {app }}$ was found to be variable depending on the value of $C_{\mathrm{r}}$, and to reach a maximum at about $C_{\mathrm{r}}=0.6$.

By means of the method of least squares, the value for $D_{\text {app }}$ could be expressed as a quadratic equation of $C_{\mathrm{r}}$ as follows:

$$
D_{\text {app }}=A \times C_{\mathrm{r}}^{2}+B \times C_{\mathrm{r}}+C
$$




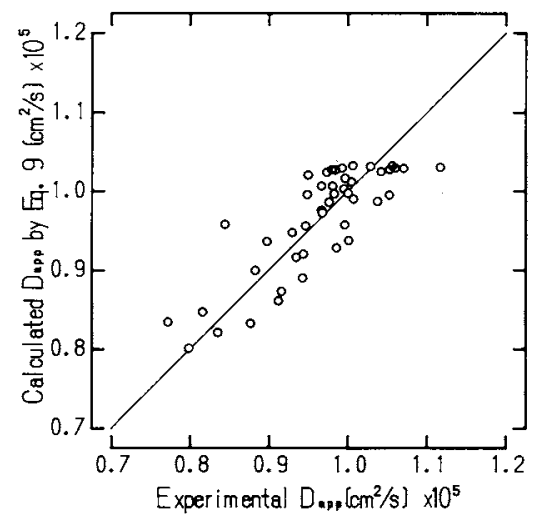

Fig. 5. Correlation between the Calculated and Experimental Values for $D_{\mathrm{app}}$.

The total number of data, correlation coefficient and standard error are $n=45, R=0.8314$ and S.E. $=4.431 \times$ $10^{-2}$, respectively.

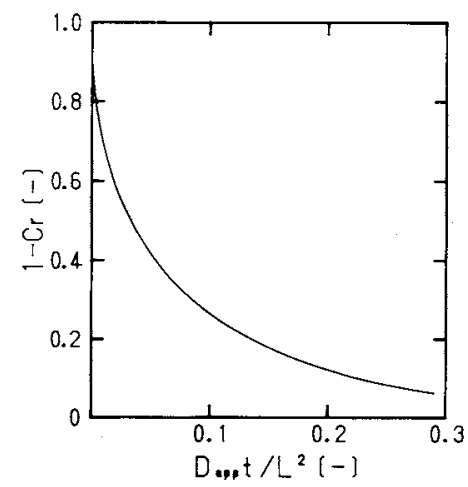

Fig. 6. Relationship between $1-C_{\mathrm{r}}$ and $D_{\mathrm{app}} t / L^{2}$.

The calculated value for $D_{a p p}$ from Eq. (9) was used.

where $A=-1.064 \times 10^{-5}, \quad B=1.236 \times 10^{-5}$, and $C=6.738 \times 10^{-6}$. By employing Eq. (9), the continuous value for $D_{\text {app }}$ depending on $C_{\mathrm{r}}$ could be obtained as shown by the solid curve in Fig. 4.

The correlation between the experimental value for $D_{\text {app }}\left(D_{\text {exp }}\right)$ and calculated one $\left(D_{\text {cal }}\right)$ by Eq. (9) is shown in Fig. 5. The total number of data (the value for $D_{\text {app}}$ ) was 45 , the correlation coefficient was 0.8314 and the standard error for $D_{\text {exp }} / D_{\text {cal }}=1$ was $4.431 \times$ $10^{-2}$.

Relationship between $C_{\mathrm{r}}$ and $D_{\mathrm{app}} t / L^{2}$

By employing the value for $D_{\text {app }}$ of Eq. (9),

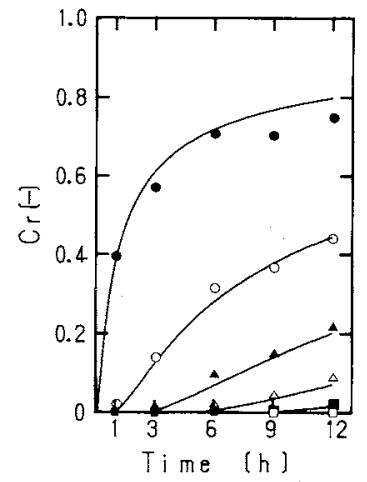

Fig. 7. Changes in $C_{\mathrm{r}}$ for a Semi-infinite Agar Slab after Soaking in a $0.1 \mathrm{M}$ Sodium Chloride Solution.

Experimental values are shown by symbols: $0.25 \mathrm{~cm}$; $0,0.75 \mathrm{~cm} ; \boldsymbol{\Delta}, 1.25 \mathrm{~cm} ; \Delta, 1.75 \mathrm{~cm} ; \boldsymbol{\square}, 2.25 \mathrm{~cm} ; \square$, $2.75 \mathrm{~cm}$; which represent the distance from the surface in contact with the sodium chloride solution to the center of each sliced sample. The solid curves represent the calculated value from Eq. (8) using $D=1.12 \times 10^{-5} \mathrm{~cm}^{2} / \mathrm{sec}$.

the relationship between $1-C_{\mathrm{r}}$ versus $D_{\mathrm{app}} t / L^{2}$ was obtained as shown in Fig. 6. The experimental value estimated from this solid curve is also shown as the solid curves in Fig. 2 , and the curves agreed well with the experimental ones. In this way, we can obtain the curve of $C_{\mathrm{r}}$ versus $t$ for various sizes of cubes by using the solid master curve shown in Fig. 6.

\section{Diffusion coefficient in semi-infinite media}

The values for $C_{\mathrm{r}}$ in a semi-infinite agar gel slab are shown in Fig. 7 by symbolic marks. The value for diffusion coefficient $D$ obtained by best-fitting Eq. (8) to the experimental value was $1.12 \times 10^{-5} \mathrm{~cm}^{2} / \mathrm{sec}$. The solid curves in Fig. 7 were drawn by using the obtained $D$ value. This $D$ value is a little less than that reported formerly, ${ }^{6)} 1.27 \times 10^{-5} \mathrm{~cm}^{2} / \mathrm{sec}$, because of the difference in agar used.

\section{Discussion}

In order to reveal the actual transport profile of seasonings or additives in foods, the transport of sodium chloride in $2 \%$ agar gel cubes was investigated, and the changes in the apparent diffusion coefficient $\left(D_{\text {app }}\right)$ for three- 
dimensional diffusion were revealed.

The value for $C_{\mathrm{r}}$

The value for $C_{\mathrm{r}}$, which represents the ratio of the mean concentration of sodium chloride in the gel to the boundary concentration, depends on both the side length of the cube and the soaking period, as shown in Fig. 2. By employing the value for $t / L^{2}$ as a variable, $C_{\mathrm{r}}$ could be expressed as a function of this as shown in Fig. 3.

\section{Features of $D_{\text {app }}$ for three-dimensional diffusion}

The value for $D_{\mathrm{app}}$ depended on $t / L^{2}$ and $C_{\mathrm{r}}$, and had a maximum as shown in Fig. 4. Furthermore, for all values of $t / L^{2}$ or $C_{r}$, the $D_{\text {app }}$ in cubes was found to be less than that obtained in a semi-infinite slab. Even the maximum $D_{\text {app }}$ in the cube was $8 \%$ less than the $D_{\text {app }}$ in the semi-infinite slab.

The relationship between $C_{\mathrm{r}}$ and $D_{\mathrm{app}} t / L^{2}$

In this investigation, an attempt was made to recognize a relationship among the size of a cube, the immersion time, the mean concentration of sodium chloride in the cube and $D_{\text {app. }}$. The relationship among these, shown in Fig. 6, can be applied to the diffusion of substances in various kinds of food materials other than agar gel. After undertaking the experiment with one size of cube for a certain food material, the value for $D_{\text {app }}$ and the mean concentration of various sizes of cube of the food material can be predicted from the solid curve in Fig. 6.

\section{The dependence of $C_{\mathrm{r}}$ on $D_{\mathrm{app}}$}

Figure 4 shows that the value for $D_{\text {app }}$ changed from about $0.8 \times 10^{-} 5$ to $1.03 \times 10^{-5}$ $\mathrm{cm}^{2} / \mathrm{sec}$. When $D_{\text {app }}$ is assumed to be constant, it becomes $0.98 \times 10^{-5} \mathrm{~cm}^{2} / \mathrm{sec}$ by substituting all the data into Eq. (5). When the value for $C_{\mathrm{r}}$ is calculated by using this constant $D_{\text {app }}$, the maximum difference in $C_{\mathrm{r}}$ between the calculated $C_{\mathrm{r}}$ and the experimental one becomes about $\pm 6 \%$. If this difference is acceptable, Eq. 5 can be used to calculate $C_{\mathrm{r}}$, assuming that $D_{\text {app }}$ is constant.
Acknowledgment. The authors are indebted to The Salt Science Research Foundation for support of this research under grant no. 8922

\section{Nomenclature}

The symbols shown in this study are as follows.

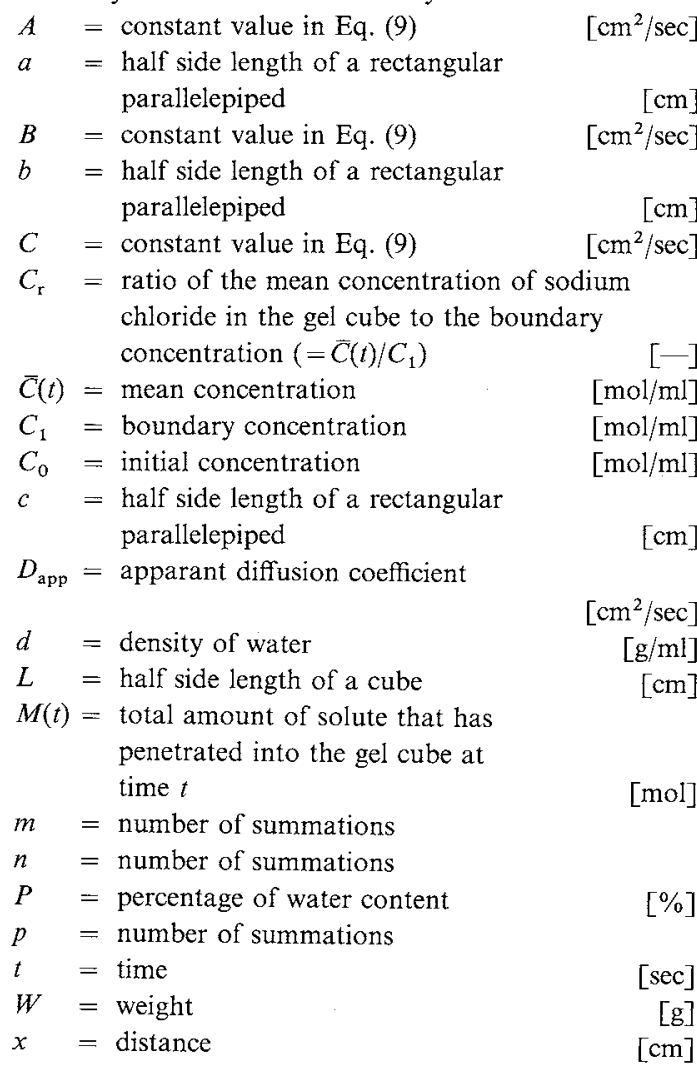

\section{References}

1) R. Stahl and M. Loncin, Food Processing \& Preservation, 1979, 213.

2) T. L. Geurts, P. Walstra and H. Mulder, Neth. Milk Dairy J., 28, 102 (1974).

3) G. Favetto, J. Chirife and G. B. Bartholomai, J. Fd Technol., 16, 609 (1981).

4) T. Fujii and H. C. Thomas, J. Phys. Chem., 62, 1566 (1958).

5) G. F. Allen, H. Schuring, L. Slade and H. C. Thomas, J. Phys. Chem., 67, 1402 (1963).

6) A. L. Slade, A. E. Cremers and H. C. Thomas, $J$. Phys. Chem., 70, 2840 (1966).

7) G. Djelveh, J. B. Gros and B. Bories, J. Food Sci., 54, $166(1989)$.

8) W. Brown and K. Chitumbo, J. Chem Soc., Faraday Trans. 1, 75, 1 (1975).

9) M. Hendrickx, C. V. Abeele, C. Engels and P. Tobback, J. Food Sci., 51, 1544 (1986). 
10) M. Sakai and M. Miki, Nippon Shokuhin Kogyo Gakkaishi, 30, 483 (1982).

11) M. Sakai and A. Suzuki, Nippon Shokuhin Kogyo Gakkaishi, 32, 480 (1985).

12) The Japan Society for Analytical Chemistry (Hokkaido), "Analysis of Water," Kagakudojin Co.,
Kyoto, 1981, pp. 176-178.

13) R. B. Bird, W. E. Stewart and E. N. Lightfoot, "Transport Phenomena," John Wiley and Sons, New York, 1960, p. 373.

14) J. Crank, "The Mathematics of Diffusion," Clarendon Press, Oxford, 1975, pp. 20-21. 